\title{
Trainee Therapists' Experiences of Supervision during Training: A Meta-synthesis
}

Dr Hannah M N Wilson

Lancashire Care NHS Foundation Trust, UK

Dr Jenny S Davies

Lancaster University, UK

Dr Stephen Weatherhead

Lancaster University, UK 


\begin{abstract}
Purpose: Supervision is typically mandatory for therapists in training, and plays an important role in their professional development. A number of qualitative studies have considered specific aspects of supervision. This systematic review aimed to synthesise these studies' findings, and explore the experience and impact of supervision for trainee therapists.

Methods: A systematic search of the literature was conducted, and inclusion/exclusion criteria were applied. This led to a sample of 15 qualitative studies, with which a metasynthesis was conducted.
\end{abstract}

Results: The meta-synthesis led to four key concepts: Supervision as a learning opportunity; the supervisory relationship; power in supervision; and the impact of supervision. These themes explored helpful and unhelpful aspects of supervision, including some concerns regarding the evaluation of supervision.

Conclusions: Supervision can effectively support trainee therapists in their personal and professional development. However, it can also lead to feelings of distress and self-doubt. Supervisors need to consider the power differential within supervision, and attend to different factors within the supervisory relationship.

\title{
Practitioner points:
}

- Supervision can encourage personal and professional development, but it can also have a detrimental impact on trainee therapists’ wellbeing, and consequently their clinical work and clients’ experiences

- Supervisees may not disclose unhelpful events or impacts from supervision, for fear of negative evaluation

- Evaluation of supervisors should be facilitated and encouraged, to maintain good practice 
Keywords: meta-synthesis; qualitative; supervision; therapists in training

\section{Trainee Therapists' Experiences of Supervision during Training: A Meta-synthesis}

Supervision is defined by the British Psychological Society (BPS)'s Division of Counselling Psychology as “designed to offer multi-level support in an atmosphere of integrity and openness for the purpose of enhancing reflective skills, maximising the effectiveness of therapeutic interventions, informing ethical decisions and facilitating an understanding of the use of self” (2005; p.5). Accessing supervision during training is considered vital across a range of psychological models and disciplines (Wheeler \& Richards, 2007). The American Psychological Association (APA; 2014), Australian Psychological Society (APS; 2003) and BPS (2013) all specify a minimum level of contact time with supervisors during practitioner training. Similarly, the British Association for Counselling and Psychotherapy (2002) dictate all practising counsellors and therapists should receive supervision, regardless of career stage.

Supervision is mandatory for therapists in training, but its function and style can vary. This review will first consider the purpose of clinical supervision for therapists training to deliver talking therapies through an accredited programme ${ }^{1}$. It will then explore the importance, efficacy and quality of supervision, before presenting a meta-synthesis of studies regarding these experiences.

\section{Purpose of Supervision}

Supervision has been described as an "essential prerequisite for the practice of psychotherapy” (Roth \& Fonagy, 1996, p. 373), which aims to ensure clients receive a good service, and develop a supervisee’s competence (Falender \& Shafranske, 2004). The BPS (2008) suggests “all aspects of practice should be accessible to discussion in supervision including research activity, administrative and managerial work, service developments, team

\footnotetext{
${ }^{1}$ Programmes are accredited by various bodies in different countries, such as the American Psychological Association, Australian Psychological Society, and the British Psychological Society
} 
working, teaching and the process of supervising others” (p. 16). Supervision also provides an opportunity to socialise trainees to the profession and particular models (Falender \& Shafranske, 2004). The feedback and reflection which supervision provides is considered essential to trainees acquiring and developing skills, which would not occur through exposure to clinical work alone (Bernard \& Goodyear, 2013; Binder, 1993).

In addition to supporting skill development, supervision is expected to monitor ethical and professional behaviour (Milne \& James, 2000; Wheeler, 2004). It can also provide emotional support to trainee therapists (De Stefano et al., 2007). Enhanced trainee confidence, motivation and therapeutic perceptiveness are potential outcomes from positive supervisory experiences (Nelson \& Friedlander, 2001). Self-efficacy has been described as “the primary causal determinant of effective counselling action” (Larson \& Daniels, 1998, p. 180), and therefore anything which contributes to its development is worthy of attention.

There is an inevitable element of evaluation within supervision for trainee therapists. Whilst assessing supervisees’ performance, the supervisor retains ultimate responsibility for their work (Falender et al., 2004). There has been an increase in emphasis on supervised practice in response to greater demands for accountability within the National Health Service (Wheeler, 2004). This increased pressure on certain functions of supervision may affect the supervisory relationship, as "both supervisor and supervisee can experience evaluation with discomfort” (Bernard \& Goodyear, 1998, p. 9). There has been minimal research exploring the evaluative component of supervision, and how supervisors judge trainee competence (Bambling, King, Raue, Schweitzer, \& Lambert, 2006). This may be partly due to the noted discomfort, and consequently focussing on aspects of supervision such as the relationship or model.

Whilst supervisors may be informed by different supervisory models, the core aims of supervision remain the same: Teaching and learning; and monitoring clients' welfare 
(Bernard \& Goodyear, 2013). These aims have a number of potential impacts upon clients' and trainees' experiences.

\section{Impact of Supervision}

Efforts to quantify the efficacy of supervision have met methodological difficulties (Wheeler, 2004), with Ellis and colleagues suggesting that falsely significant results are likely to be detected (Ellis, Ladany, Krengel \& Schult, 1996). More recently, Milne and James (2000) conducted a review of cognitive behavioural supervision, and demonstrated positive impacts on client outcomes. However, these outcomes relied predominantly on simple behavioural measures; therefore the significance of their findings is unclear.

Whilst there is a lack of strong empirical evidence to support direct links between supervision and client outcome (Wheeler \& Richards, 2007), some authors have explored indirect impacts. A review by Holloway and Neufeldt (1995) outlined several factors which contribute to treatment efficacy, which supervision may affect. These included the therapist's ability to: Case conceptualise; select and conduct interventions; and follow intervention plans consistent with specific models. Supervision also supports supervisees to increase their selfawareness and recognise their "blind spots" (Morrissey \& Tribe, 2001, p. 105; Wheeler \& Richards, 2007). Increased self-awareness may enable therapists to better distinguish between the emotions of themselves and their clients (Kumari, 2011). However, it is difficult to know how much development can be attributed to supervision, as opposed to the cumulative experience of training itself.

In addition to self-awareness, supervision can affect a trainee’s professional confidence (Nelson \& Friedlander, 2001; Wulf \& Nelson, 2001). Where trainees perceive failure within their clinical work, supervision can support their continued self-competence (De Stefano et al., 2007). The perceived safety of supervision is likely to impact on the disclosure of trainee fears and vulnerabilities. Providing emotional support during 
supervision can reduce the likelihood of trainees being distracted by their emotions within clinical work (Vallance, 2004), and provides an opportunity to normalise difficult experiences (Knox, Burkard, Jackson, Schaak, \& Hess, 2006).

\section{Quality of Supervision}

Due to the inherently personal nature of supervision, it is difficult to define successful supervision (Milne, Pilkington, Gracie \& James, 2003). Falender and Shafranske (2004) suggest effective supervision is built on three aspects: The supervisory relationship; thinking critically about therapeutic processes; and learning strategies.

Carifio and Hess (1987) claimed:

High-functioning supervisors perform with high levels of empathy, respect, genuineness, flexibility, concern, investment, and openness. Good supervisors also appear to be knowledgeable, experienced, and concrete in their presentation. They use appropriate teaching, goal-setting, and feedback techniques during their supervisory interactions. Last, good supervisors appear to be supportive and noncritical individuals who respect their supervisees (p. 244).

Throughout the wealth of research exploring supervision, the relationship between supervisor and supervisee is highlighted as the most important factor in its success (Holloway, 1995; Kilminster \& Jolly, 2000; Ladany, Ellis \& Friedlander, 1999). The BPS (2013) stipulates "supervisors should be sensitive to, and prepared to discuss, personal issues that arise for trainees in the course of their work” (p. 31). Collaboration between supervisor and supervisee has been highlighted as a key component of supervision (Ratcliff, Wampler \& Morris, 2000), with elements such as trust, understanding and acceptance highly valued (Wheeler, 2004). As the supervisor plays the role of "evaluator, assessor, gatekeeper and transmitter of values for the profession” (Patel, 2004, p. 109), it is important to acknowledge the power dynamics within the supervisory relationship. Patel suggests failure to explicitly 
address the power relations within supervision can lead to coercion, as opposed to collaboration, which may negatively impact client work.

\section{Rationale for a Meta-synthesis}

Supervision for therapists in training is an important issue to explore, not least because "about one half of a professional psychologist's formal training involves learning through supervision” (Bent, Schindler, \& Dobbins, 1991, p. 124). Much of the past research regarding supervision has involved responses to questionnaires, which lack the ability to fully explore what happens within supervision (Reichelt \& Skjerve, 2001).

More recently, a number of qualitative studies have been conducted to investigate particular aspects of supervision, such as self-disclosure or perspectives of power. This can provide a richer understanding of supervisees' experiences than quantitative studies, as exemplified by Milne et al. (2003) in their exploration of the transference of skills from supervision to therapy. Although the specific focus of these qualitative studies can limit their generalisability, there may be common factors which feature across each of these specific experiences. Having a broader understanding of this may be of benefit to supervisors and supervisees.

Although supervision requirements vary across countries, disciplines and therapeutic orientations, it is typically mandatory for trainees (Wheeler \& Richards, 2007). In addition, training may be the time where supervision has the most influence, as trainees rapidly gain both experience and skills. Therefore, this meta-synthesis looks at the experiences of supervision for therapists in training. As there has historically been a lack of effort to provide training or support for supervisors (Milne \& James, 2002), it is hoped that additional information regarding supervisory encounters will support supervisors to provide effective supervision. 


\section{Method}

The aim of a qualitative meta-synthesis is to develop new knowledge, based on analysis and synthesis of existing qualitative research (Thorne, Jensen, Kearney, Noblit \& Sandelowski, 2004). Using a systematic approach, individual findings are examined, interpreted and integrated into conclusions more substantive than those from the original investigations (Finfgeld, 2003).

\section{Data Collection}

The following databases were searched in January 2014: MedLine; PsycArticles; PsycInfo; Web of Science. A Boolean search was conducted to allow the following terms and phrases to be combined:

- Psychologist in training OR trainee psychology* OR trainee therap* OR psycholog* graduate OR therap* training OR psycholog* intern OR therap* student OR psycholog* student OR trainee counsel*

- Qualitative OR interview OR focus group

- Supervis*

No other expanders or limiters were selected. A total of 104 papers were screened for eligibility.

The following inclusion criteria were applied, in order for studies to be considered: Written in English; qualitative design using interviews or focus groups; exploring experiences of previous supervision; concerning therapists in training.

Studies which met the inclusion criteria were further examined, and exclusion criteria applied as follows. Studies were excluded if the analysis incorporated merged responses from both supervisors and therapists in training, where data could not be extracted and interpreted individually.. Where both supervisor and supervisee responses were presented separately, studies were included and the trainee responses were included in the analysis.. 
Studies were also excluded if the findings presented were not well supported by raw data i.e. if direct quotes were not provided to support the themes or concepts described (Finfgeld, 2003). Finally, any studies whose findings were not presented as themes were also excluded. This was to better enable comparison and contrast across the studies (Sandelowski, Docherty, \& Emden, 1997). This process led to a final sample of 15 studies.

Figure 1 around here

\section{Appraising the Quality of the Selected Studies}

The quality of the studies was assessed using the Critical Appraisal Skills Programme (CASP, 2013), which comprises 10 items appraising the credibility, rigour and relevance of the research. This allows description of the range of quality within the studies, and reflection on the contribution of different quality papers to the final synthesis (Atkins et al., 2008). As suggested by Duggleby et al., (2010), a score was assigned for each item. A '3' denoted presenting extensive justification and meeting criteria, '2' denoted addressing, but not elaborating on, the issue, and ' 1 ' denoted a substantial lack in meeting the criteria or presenting any justification. The scoring was completed by the principal researcher, and discussed within a research group of other narrative researchers. This allowed any differences in opinion to be discussed, and a consensus to be reached. No studies received a ' 3 ' on all items, but the majority were of relatively good quality. Items such as appropriate design, reflexivity and ethical concerns were commonly not fully met. The total score of the studies ranged from 17 to 26 (max 30).

\section{Characteristics of the Selected Studies}

This meta-synthesis includes data from 165 participants across 15 separate studies. The papers were published across a 16 year period, between 1996 and 2012. Demographic 
and descriptive data regarding the participants and methods within the 15 studies is presented in Table 1.

Table 1 around here

The sample includes a variety of therapists in training, including clinical and counselling psychologists, and family therapists. Nine of the 15 studies took place within the USA, three in the UK and one each in Australia, Canada and Norway. Almost 61\% of participants were female.

\section{Data Analysis}

The goal of a qualitative meta-synthesis lies in interpretation rather than aggregation (Thorne et al., 2004). In order to achieve a synthesis of the papers whilst preserving the data within, a meta-ethnographic method was followed as described by Noblit and Hare (1988). This approach's process of induction and interpretation is suggested to more closely resemble the qualitative methods of those studies it seeks to synthesise than some traditional methods (Britten et al., 2002).

Noblit and Hare describe a seven-step process when conducting a meta-ethnography: Getting started; deciding what is relevant; reading the studies; determining how studies are related; translating studies into one another; synthesising translations; and expressing the synthesis. These steps are iterative, rather than a discrete, linear process (Pope, Mays \& Popay, 2007). Steps one and two were achieved through conducting a literature search and applying both inclusion and exclusion criteria to determine the relevant studies. The included papers were read several times, to familiarise the author with the content. Whilst reading each paper, concepts, themes and interpretations presented by the authors were noted. The 
concepts or metaphors from each paper were then compared and contrasted, to explore if and how the studies were related.

A reflective journal was kept throughout the process, to acknowledge and explore any biases or assumptions held by the researcher. This informed discussions within supervision sessions, such as noticing a potential focus on the negative aspects of supervision and whether this accurately reflected the data.

This process developed a set of key concepts, which encompassed the themes and metaphors within each paper. The data were examined for any themes, metaphors or concepts which refuted the developing interpretation. The final synthesis was expressed as four key concepts. Table 2 demonstrates which studies contributed to each key concept.

Table 2 around here

\section{Findings}

The findings presented below reflect the themes and interpretations described within the selected studies, and are grouped into the following concepts: Supervision as a learning opportunity; the supervisory relationship; power in supervision; and the impact of supervision.

\section{Supervision as a Learning Opportunity}

Thirteen of the studies included themes relating to different learning opportunities which arose from supervision. Some participants appreciated supervisors who encouraged them to discover their own answers (Johnston \& Milne, 2012), whilst others said that "at times I feel that he is bating me to something he has thought out himself. He should rather be clear about it than keep me guessing” (Reichelt \& Skjerve, 2001, p. 34). 
Feedback from supervisors was thought to enable participants’ learning, and encourage their development (Worthen \& McNeill, 1996). This could be providing “expert opinions on how supervisees’ skills needed to change” (Murphy \& Wright, 2005, p. 288) or noting positives in supervisees’ performance. Participants also valued supervisors providing advice on alternatives (Bottrill et al., 2010; De Stefano et al, 2007; Folkes-Skinner et al., 2010; Murphy \& Wright, 2005; Reichelt \& Skjerve, 2001). This included alternative ways to approach particular issues, and possible explanations for participants’ own feelings such as frustration or incompetence (Bottrill et al., 2010; De Stefano et al., 2007; Folkes-Skinner et al., 2010). It was important that alternative suggestions were not accompanied by pressure to act on them (Murphy \& Wright, 2005; Reichelt \& Skjerve, 2001).

Observation of supervisors was suggested to contribute significantly to participants’ learning and development (Bottrill et al., 2010; Burkard, Knox, Hess \& Schultz, 2009; Gray et al., 2001; Rhodes, Nge, Wallis \& Hunt, 2011; Wulf \& Nelson, 2001). Participants appreciated supervisors who demonstrated values such as respect for others and honesty regarding their fallibility.

Participants appreciated supervisors who facilitated thinking about the “metaperspective” (Worthen \& McNeill, 1996, p. 31) such as the purpose of therapy, the therapeutic relationship, and theories of change (Bottrill et al., 2010). Reflection on supervision allowed the learning process to continue beyond the session (Johnston \& Milne, 2012; Wulf \& Nelson, 2001). For some participants, there was a lack of opportunity for reflection within supervision (Bottrill et al., 2010), which could "leave them feeling that they had to figure things out for themselves without sufficient support” (p. 174). This diminished focus on reflection could result from time pressures, and fears of negative evaluation for raising particular topics. 
The different learning opportunities within supervision allowed participants to build their confidence and professional identity (Ancis \& Marshall, 2010; Murphy \& Wright, 2005; Perry, 2012; Worthen \& McNeill, 1996). Supervisors who “empowered by emphasising and capitalising on supervisees’ knowledge and wisdom” (Murphy \& Wright, 2005, p. 288) encouraged participants to make confident decisions regarding their clients.

\section{Supervisory Relationship}

Positive and negative aspects of the supervisory relationship were discussed in 11 of the papers. Worthen and McNeill (1996) state "the most pivotal and crucial component of good supervision experiences... was the quality of the supervisory relationship” (p. 29). Words used to describe positive supervisory relationships included “supportive,” “caring,” “open,” “collaborative,” “sensitive,” “flexible,” "helpful,” “non-judgemental,” “inquisitive,” and “challenging” (Gray et al., 2001; Johnston \& Milne, 2012; Marshall \& Wieling, 2003; Murphy \& Wright, 2005; Reichelt \& Skjerve, 2001; Worthen \& McNeill, 1996). One participant suggested this was a combination of "personal caring but with never a loss of sight of the professional” (Wulf \& Nelson, 2001, p. 131). Respect was also important within the supervisory relationship, both personally and professionally, such as maintaining the agreed time or space for supervision (Johnston \& Milne, 2012; Worthen \& McNeill, 1996).

Participants appreciated supervisors who accepted and explored the differences between them, allowing supervisor and supervisee to learn together (Ancis \& Marshall, 2010; Burkard et al., 2009; Marshall \& Wieling, 2003). This enhanced the supervisory relationship, and increased participants’ confidence (Ancis \& Marshall, 2010; Marshall \& Wieling, 2003; Murphy \& Wright, 2005). Events where supervisors displayed acceptance of issues of diversity also helped to strengthen the supervisory relationship (Burkard et al., 2009; Marshall \& Wieling, 2003). 
Supervisors’ self-disclosure was perceived positively, particularly regarding their own experiences, knowledge and values (Ancis \& Marshall, 2010; Worthen \& McNeill, 1996). This helped to normalise supervisees’ experiences and encouraged participants to share their own perspectives (Ancis \& Marshall, 2010; Bottrill et al., 2010; Worthen \& McNeill, 1996). These factors contributed to developing participants' self-awareness and professional confidence. The supervisory relationship was important in facilitating this growth, which was difficult when “sometimes people don’t fit with their supervisors” (Wulf \& Nelson, 2003, p. 138).

There was also discussion of negative events in supervision. This was largely explored in papers with a specific focus on negative aspects of supervision, but was also briefly discussed in other included studies. Where these events occurred, the safety of the supervisory relationship was greatly impacted (Burkard et al., 2009; Gray et al., 2001). This could lead participants to cease addressing clinical issues with their supervisor, and affected their sense of being “good enough” (Gray et al., 2001). Words used to describe unhelpful supervisors included “impatient,” “uncommitted, "late,” “inconsistent,” and "not empathic” (Gray et al., 2001; Johnston \& Milne, 2012; Nelson \& Friedlander, 2001). Although possible for supervisory relationships to improve or recover, this required acknowledgement and support from the supervisor. Alternatively, it required an adaptation from the trainee, such as growing “thicker skin” (Gray et al., p. 377).

Aspects of supervision experienced as less helpful included unproductive or unprepared sessions/supervisors, and displaying favouritism (Burkard et al., 2009; Murphy \& Wright, 2005). Supervisors could also be “preoccupied with his or her own ideas” (Reichelt \& Skjerve, 2001, p. 32). One participant described a supervisor who "whenever I criticized his criticism, he would just get furious. He screamed at me a couple of times; just weird stuff.” (Wulf \& Nelson, 2001, p. 130). Although participants wished their supervisors had 
acknowledged counterproductive events in supervision, their feelings were typically undisclosed to supervisors. Consequently, the event was unresolved (Gray et al., 2001; Nelson \& Friedlander, 2001).

\section{Power in Supervision}

Aspects of power in supervision were explored by nine of the studies, with supervisors either implicitly or explicitly discussing it (Ancis \& Marshall, 2010; Murphy \& Wright, 2005). The experience and impact of the power differential appeared to be more significant than other aspects of the supervisory relationship, and consequently it was explored within a separate theme. Negative supervision events often centred on aspects of power, such as dismissing participants' thoughts and feelings, or supervisors exploring their own agenda (Gray et al., 2001; Johnston \& Milne, 2012; Nelson \& Friendlander, 2001).

Certain aspects of supervision were inextricably linked to concepts of power, particularly evaluation (Bottrill et al., 2010; Johnston \& Milne, 2012; Murphy \& Wright, 2005; Wulf \& Nelson, 2001). Although participants recognised the importance of learning their own strengths and weaknesses, fear of negative evaluation impacted on their comfort in raising difficult topics in supervision (Bottrill et al., 2010; Burkard et al., 2009; Gray et al., 2001). One participant commented, “it’s intrinsically quite a threatening process to go into; to be honest and open so that you can benefit, but doing that with the person that's your judge and executioner” (Johnston \& Milne, 2012, p. 11). When participants felt able to initiate discussions of counterproductive events within supervision, there could be both positive and negative consequences (Gray et al., 2001; Nelson \& Friedlander, 2001). Some participants also perceived their supervisor as "biased or oppressive” (Burkard et al., 2009) based on their reactions to topics such as sexual orientation.

Participants reported direct violations of supervisors' power, such as sharing inappropriate information or following their own agenda (Murphy \& Wright, 2005; Nelson \& 
Friedlander, 2001). One participant’s supervisor revealed "highly explicit details of his sexual activities to her” (Nelson \& Friedlander, 2001, p. 390). The participant feared possible recriminations if she complained, and consequently remained silent. Where difficulties in the supervisory relationship occurred, supervisees felt "uncertain and unsafe in supervision” (Burkard et al., 2009, p. 183) and began to distrust their supervisor’s advice. Instances where participants felt powerless in supervision could also lead to feelings of stress and self-doubt, assuming “it must be what I am doing. It must be my fault” (Nelson \& Friedlander, 2001, p. 291).

Supervisors’ misuse of power, such as intrusive actions or breaking confidentiality, led to an unsafe supervisory relationship (Burkard et al., 2009; Murphy \& Wright, 2005, p. 290). This led participants to distrust their supervisor's advice, or self-criticise (Burkard et al., 2009; Gray et al., 2001). In contrast, supervision perceived as safe was described with words such as “confidential,” “open,” “non-judgemental,” “supportive,” and demonstrated “an effective use of power” (Ancis \& Marshall, 2010; Murphy \& Wright, 2005). Feeling safe within supervision allowed participants to be vulnerable, and take risks in questions or challenges (Ancis \& Marshall, 2010; De Stefano et al, 2007; Gray et al., 2001; Murphy \& Wright, 2005). Where participants did not experience this safety, they often chose not to disclose their own feelings, which could impact on their clinical development (Murphy \& Wright, 2005).

Although the majority of themes regarding power referred to the supervisor, there were also responses regarding power held by the supervisee (Ancis \& Marshall, 2010; Murphy \& Wright, 2005). Participants were empowered by the ability to warn peers about supervisors who were not experienced as competent or respectful. They also recognised the possibility of raising complaints as a group with their program director. 


\section{Impact of Supervision}

There were several impacts of supervision described by participants, both personally and professionally. Participants described feeling "affirmed, validated, and respected” when supervisors reacted positively to their identities (Burkard et al., 2009, p. 182). Normalising participants” feelings was also “comforting” and “reassuring” (Folkes-Skinner et al., 2010) and helped to increase confidence in client work (Worthen \& McNeill, 1996).

Supervision provided a space to process feelings, both regarding clients and colleagues (Burkard et al., 2009; Rhodes et al., 2011; Worthen \& McNeill, 1996), although some participants wanted more opportunity to discuss personal aspects of the therapist role (Reichelt \& Skjerve, 2001). Participants valued the safety to discuss the links between personal and professional issues, and suggested these opportunities allowed the development of an internal supervisor (Rhodes et al., 2011; Worthen \& McNeill, 1996).

Supervisors were able to comment on trainee strengths and weaknesses, which was received both positively and negatively (Ancis \& Marshall, 2010; Wulf \& Nelson, 2001). Where feedback was overly negative, participants could feel they were "being picked at and criticized a lot” (Wulf \& Nelson, 2001, p. 129). Negative events like this could lead to emotions such as anger, fear, distress, frustration, anxiety and shock (Burkard et al., 2009; Gray et al., 2001). Participants described losing trust in their supervisor and withdrawing from the relationship (Nelson \& Friedlander, 2001).

Participants managed counterproductive events in supervision by "trying to be agreeable or trying not to be defensive” (Gray et al., 2001, p. 376). However, feelings of self-doubt and confusion were often experienced. Some participants strove to recognise their own role in the supervisory difficulties, and utilised support from others (Nelson \& Friedlander, 2001). Coping successfully with episodes of conflict or negativity strengthened some participants' sense of self and resilience (Nelson \& Friedlander, 2001). However other 
participants' sense of self became uncertain as they felt pressured to be a "clone” of their supervisor (Wulf \& Nelson, 2001, p. 134). Some also began to doubt their profession’s level of acceptance and knowledge, reflecting “I don’t think I want to be involved with the hard line mental health type attitude or people” (Burkard et al., 2001, p. 391).

Participants reported a number of ways in which supervision affected their client work. They were encouraged to understand the client's perspective, including "the relationship between a client’s presenting problem, situational events, and diversity considerations” (Ancis \& Marshall, 2010, p. 281). Participants appreciated when supervision included space to reflect on their relationship with their clients (Reichelt \& Skjerve, 2001). Open discussions in supervision were also thought to positively affect outcomes with clients (Ancis \& Marshall, 2010; Burkard et al., 2009). This included an increased sensitivity to emotive clinical issues and greater confidence working with diverse clients.

\section{Discussion}

This meta-synthesis drew upon the experiences of 165 participants across 15 studies. The analysis led to four key concepts. The results indicate supervision provides a number of different learning opportunities, but their success depends largely upon the supervisory relationship. Aspects of power appear to significantly influence experiences of supervision, the impact of which can be felt personally and professionally.

Participants discussed a number of functions which supervision can fulfil, often related to its role in teaching or learning. Developing supervisee competence and ensuring the quality of the client's service are described as the two key roles of supervision (Bernard \& Goodyear, 2013; Falender \& Shafranske 2004). This meta-synthesis suggests trainees are focussed on the former. This may be partly due to their awareness of being evaluated, and consequently focussing on their own performance. Although facilitating a trainee's professional development should subsequently enhance therapy outcomes for clients (Ellis \& 
Ladany, 1997), it may be unhelpful if supervisors and supervisees differ in their aims or focus of supervision. Research has suggested supervisor-supervisee complementarity has a substantial influence on the supervisory working alliance (Chen \& Bernstein, 2000). Qualitative studies have also suggested feelings of incompetence can arise from discrepancies between the feedback expected and provided within supervision (De Stefano et al., 2007). This has several implications for supervisors. Supervisors should be supported to facilitate discussions with supervisees regarding hopes and expectations for supervision. They should also encourage trainees to seek routine feedback from service users (Lambert et al., 2001), to ensure the client remains within focus.

Participants’ descriptions of helpful supervision often related to the supervisory alliance, including a supportive supervisor and feeling safe within the relationship. Although many of the included studies explored a particular supervisory focus or event, these aspects were considered globally beneficial. These findings are supported within the literature regarding "good” supervision (Cushway \& Knibbs, 2004; Kilminster \& Jolly, 2000; Wheeler, 2004). Participants' responses suggest experiences of supervision could be understood within models of attachment (e.g., Bowlby, 1969). Pistole and Watkins (1995) discuss how supervisors can become a safe base, which enables supervisees to explore and develop in confidence. This safety is facilitated by qualities such as consistency, empathy and warmth, which were noted by participants in this study.

The utility of a supervisor's approach may depend on a supervisee’s perception of their supervisor’s intentions. For example, some participants appreciated supervisors supporting them to discover their own answers (Johnston \& Milne, 2012). Conversely, other participants felt their supervisor was "bating me” by not disclosing the answer (Reichelt \& Skjerve, 2001, p. 34). This highlights the need for flexibility by supervisors. Some supervisors may begin to assume a particular approach is helpful, especially if they receive 
positive feedback. However, supervisors should continue to facilitate discussions regarding a supervisee’s preferred way of working in supervision, and their response to sessions.

Power within supervision was referred to by the majority of included studies. Patel (2004) suggests power relations are present within all aspects of the process. Some violations of power described by participants raise concerns regarding supervisors’ conduct, including “he screamed at me” (Wulf \& Nelson, 2001, p. 130) and disclosing inappropriate information (Nelson \& Friedlander, 2001). These responses highlight a need to consider the evaluation of supervisors themselves. The APS (2013) suggest "when members provide supervision, they must be competent to do so” (p.3) but do not provide guidance on measuring or ensuring this. The BPS (2013) requires training courses to have a "formal, documented audit process for clinical placements and supervision” (p. 31). However, no participants described providing feedback to their course on negative supervision events. Trainee therapists have previously indicated difficulties in being honest when evaluating their supervisors (O’Donovan, Dyck \& Bain, 2001). This may be affected by numerous factors, including if the trainee wishes to work in the supervisor's service or speciality, and fearing the consequences of raising concerns. Training courses should consider providing supervision for supervisors, and facilitating opportunities for discussion/reflection on supervision within training. It may also be helpful to enable provision of anonymous feedback on supervision, or enabling discussions with an individual external to the course without an evaluative role.

In addition to aspects already discussed, supervisor training should encourage supervisors to discuss the supervisory process with supervisees, as supported by the APS (2013) and BPS (2008). Furthermore, supervisor training should explore provision of feedback, and how to ensure it is useful and appropriate.

It may also be beneficial to facilitate training for supervisees. Green (2004) suggests a role for incorporating this into therapy training programmes, which would include skills 
such as delivering thorough clinical reports. This could also address aspects such as the different roles of supervision, coping strategies for difficult situations and possible ways to deliver and receive feedback. Training for both supervisors and supervisees should emphasise the importance of creating a supervision contract at the placement outset, as it can address a number of aspects highlighted by participants (Driscoll, 2000).

\section{Limitations}

The studies included within this meta-synthesis drew upon the experience of trainee therapists from various theoretical orientations and therapeutic backgrounds. Although each participant was training to deliver a talking therapy, there may be important differences between these groups which affect their experiences of supervision. Supervisions which adopt a particular psychological approach can differ significantly in their structure, and consequently comparison may not be entirely possible. However, the key goals of supervision remain the same, and therefore it is of value to note the "meta-perspective:" the aspects of supervision which are valued regardless of model or orientation.

There is a clear gender bias within the studies, with many more females participating. This is likely due to the gender inequality of therapists generally; the American Psychological Association suggest men represent only 24\% of new psychology doctorates (Willyard, 2011), whilst in the UK 17\% of applications for clinical psychology training in 2013 were male (Clearing House for Postgraduate Courses in Clinical Psychology, 2013). Nine of the studies took place within the USA, and a further three in the UK. Consequently, the results are not generalizable to all trainee therapists, particularly those outside the Western culture. The understanding and interpretation of mental illness varies widely across different cultures (Abdullah, 2011; Rao, Feinglass \& Corrigan, 2007). It follows that the aims and expectations for therapy, and therefore supervision, may also differ. 
As stated previously, a number of the included studies focussed on a particular aspect of supervision, such as negative events or power. Some studies also attended to specific cultural aspects, such as sexual identity or cross-cultural supervisors. This may have led some topics presented within the findings to be over-weighted. However, these aspects often related to wider issues discussed across papers, such as discussion of differences between supervisor and supervisee.

\section{Future Research}

A number of aspects highlighted by this meta-synthesis could warrant further research. This includes exploring the extent to which trainee therapists consider supervision as addressing their own competence, or the client's experience.

Substantial emphasis was placed on the process of learning together, which could arise from exploring differences between supervisor and supervisee. This implies supervision can also contribute to the professional development of the supervisor. However there is a lack of research regarding the impact of providing supervision on the supervisor themselves, which future research could work to address.

Considering the suggestion from participants that trainee therapists may not voice any difficulties they experience with supervisors, research into how trainees manage negative supervisory experiences could be of use. In addition, further exploration of how to support supervisees in addressing these experiences, including possible ways of evaluating supervisors, may be beneficial. Finally, research could examine the implementation and evaluation of Green’s (2004) proposal to include supervision training for supervisees.

\section{Conclusion}

Supervision is a valuable resource for trainee therapists, which promotes both personal and professional development. It can also provide support during the challenges of training, and ensure clients receive the best possible care. However the findings suggest 
supervision also has the potential to cause trainees to experience distress and self-doubt. Fear of negative evaluation can affect trainees' management of these events. Recognition and exploration of the power differential within supervision is important in strengthening the supervisory relationship, which in turn maximises the opportunities for trainees to learn and develop. 


\section{References $^{2}$}

Abdullah, T., \& Brown, T. (2011). Mental illness stigma and ethnocultural beliefs, values, and norms: An integrative review. Clinical Psychology Review, 31 (6), 934-948. doi: 10.1016/j.cpr.2011.05.003

American Psychological Association. (2014). Guidelines and Principles for Accreditation of Programs in Professional Psychology: Quick Reference Guide to Internship Programs. Retrieved April 12, 2014, from http://www.apa.org/ed/accreditation/about/policies/interns.aspx

*Ancis, J. R., \& Marshall, D. S. (2010). Using a multicultural framework to assess supervisees’ perceptions of culturally competent supervision. Journal of Counseling and Development, 88, 277-284. doi: 10.1002/j.1556-6678.2010.tb00023.x

Atkins, S., Lewin, S., Smith, H., Engel, M., Fretheim, A., \& Volmink, J. (2008). Conducting a meta-ethnography of qualitative literature: Lessons learnt. BMC Medical Research Methodology, 8 (21). doi: 10.1186/1471-2288-8-21

Australian Psychological Society. (2003). Guidelines on supervision. Retrieved April 12, 2014, from http://www.psychology.org.au/Assets/Files/guidelines_on_supervision.pdf

Bambling, M., King, R., Raue, P., Schweitzer, R., \& Lambert, W. (2006). Clinical supervision: Its influence on client-rated working alliance and client symptom reduction in the brief treatment of major depression. Psychotherapy Research, 16 (3), 317-331. doi: 10.1080/10503300500268524

Barbour, R. S. (2001). Checklists for improving rigour in qualitative research: a case of the tail wagging the dog? BMJ, 322, 1115-7. doi:10.1136/bmj.322.7294.1115

\footnotetext{
$2 *$ denotes studies included within the meta-synthesis
} 
Beinart, H. (2004). Models of supervision and the supervisory relationship and their evidence base. In I. Fleming \& L. Steen (Eds). Supervision and Clinical Psychology: Theory, Practice and Perspectives (pp. 36-50). East Sussex: Brunner-Routledge.

Bent, R. J., Schindler, N., \& Dobbins, J. E. (1991). Management and supervision competency. In R. Peterson (Ed.). Core Curriculum in Professional Psychology (pp. 121-126). Washington DC, USA: American Psychological Association Press.

Bernard, J. M., \& Goodyear, R. K. (1998). Fundamentals of Clinical Supervision, $2^{\text {nd }}$ edition. Massachusetts, USA: Allyn \& Bacon.

Bernard, J. M., \& Goodyear, R. K. (2013). Fundamentals of Clinical Supervision, 5th edition. Essex: Pearson.

Binder, J. (1993). Observations on the training of therapists in time-limited dynamic psychotherapy. Psychotherapy, 30, 592-598. doi: 10.1037/0033-3204.30.4.592

*Bottrill, S., Pistrang, N., Barker, C., \& Worrell, M. (2010). The use of therapist selfdisclosure: Clinical psychology trainees’ experiences. Psychotherapy Research, 20 (2), 165-180. doi: 10.1080/10503300903170947

Bowlby, J. (1969). Attachment and loss, Vol. 1.: Attachment. New York: Basic Books. Briggs, J. R., \& Miller, G. (2005). Success enhancing supervision. Journal of Family Psychotherapy, 16, 199-222. doi: 10.1300/J085v16n01_45

British Association for Counselling and Psychotherapy. (2002). Ethical framework for good practice in counselling and psychotherapy. Rugby: BACP. Retrieved February 10, 2014, from http://www.bacp.co.uk/ethical_framework/

British Psychological Society. (2005). Division of Counselling Psychology: Professional practice guidelines. British Psychological Society. Retrieved April 12, 2014, from http://www.bps.org.uk/sites/default/files/documents/professional_practice_guidelines _-_division_of_counselling_psychology.pdf 
British Psychological Society. (2008). Generic professional practice guidelines. British Psychological Society. Retrieved March 15, 2014, from http://www.bps.org.uk/sites/default/files/documents/generic_professional_practice_gu idelines.pdf

British Psychological Society. (2013). Accreditation through partnership handbook: Guidance for clinical psychology programmes. British Psychological Society. Retrieved March 15, 2014, from https://www.bps.org.uk/system/files/userfiles/Society\%20Member/clinical_accreditation_2013_web.pdf

Britten, N., Campbell, R., Pope, C., Donovan, J., Morgan, M., \& Pill, R. (2002). Using meta ethnography to synthesis qualitative research: a worked example. Journal of Health Services Research \& Policy, 7 (4), 209-215. doi:10.1258/135581902320432732

Brown, M. T., \& Landrum-Brown, J. (1995). Counselor supervision: Cross-cultural perspectives. In J. G. Ponterotto, M. J. Casas, L. A. Suzuki, \& C. M. Alexander (Eds). Handbook of Multicultural Counseling (pp. 263-286). California, USA: SAGE Publications Ltd.

*Burkard, A. W., Knox, S., Hess, S. A., \& Schultz, J. (2009). Lesbian, gay, and bisexual supervisees’ experiences of LGB-affirmative and nonaffirmative supervision. Journal of Counseling Psychology, 56 (1), 176-188. doi: 10.1037/0022-0167.56.1.176

Carifio, M. S., \& Hess, A. K. (1997). Who is the ideal supervisor? Professional Psychology: Research and Practice, 18, 244-250.

CASP. (2013). Critical Appraisal Skills Programme: Qualitative Research Checklist. Retrieved November 11, 2013, from www.casp-uk.net

Chen, E. C., \& Bernstein, B. L. (2000). Relations of complementarity and supervisory issues to supervisory working alliance: A comparative analysis of two cases. Journal of Counseling Psychology, 47, 485-497. doi: 10.1037/0022-0167.47.4.485 
Clearing House for Postgraduate Courses in Clinical Psychology. (2013). Equal Opportunities Numbers. Retrieved April 04, 2014, from http://www.leeds.ac.uk/chpccp/BasicEqualopps2012.html

Cushway, D. (1992). Stress in trainee clinical psychologists. British Journal of Clinical Psychology, 31, 169-179. doi: 10.1111/j.2044-8260.1992.tb00981.x

Cushway, D., \& Knibbs, J. (2004). Trainees’ and supervisors’ perceptions of supervision. In I. Fleming \& L. Steen (Eds). Supervision and Clinical Psychology: Theory, Practice and Perspectives (pp. 162-185). East Sussex: Brunner-Routledge.

Dennis, M., \& Aitken, G. (2004). Incorporating gender issues in clinical supervision. In I. Fleming \& L. Steen (Eds). Supervision and Clinical Psychology: Theory, Practice and Perspectives (pp. 135-161). East Sussex: Brunner-Routledge.

*De Stefano, J., D'Iuso, N., Blake, E., Fitzpatrick, M., Drapeau, M., \& Chamodraka, M. (2007). Trainees' experiences of impasses in counselling and the impact of group supervision on their resolution: A pilot study. Counselling and Psychotherapy Research, 7 (1), 42-47. doi: 10.1080/14733140601140378

Dickson, J. M., Moberly, N. J., Marshall, Y., \& Reilly, J. (2011). Attachment style and its relationship to working alliance in the supervision of British clinical psychology trainees. Clinical Psychology and Psychotherapy, 18, 322-330. doi: 10.1002/cpp.715

Driscoll, J. (2000). Practising Clinical Supervision: A Reflective Approach for Healthcare Professionals. Philadelphia, USA: Elsevier Ltd.

Duggleby, W., Holtslander, L., Kylma, J., Duncan, V., Hammond, C., \& Williams, A. (2010). Metasynthesis of the hope experience of family caregivers of persons with chronic illness. Qualitative Health Research, 20 (2), 148-158. doi:

$10.1177 / 1049732309358329$ 
Ellis, M. V., \& Ladany, N. (1997). Inferences concerning supervisees and clients in clinical supervision: An integrative review. In C. E. Watkins (Ed.). Handbook of Psychotherapy Supervision (pp. 467-507). New York, USA: Wiley.

Ellis, M. V., Ladany, N., Krengel, M., \& Schult, D. (1996). Clinical supervision research from 1981 to 1993: A methodological critique. Journal of Counseling Psychology, 43 (1), 35-50. doi: 10.1037/0022-0167.43.1.35

Falender, C. A., \& Shafranske, E. (2004). Clinical Supervision: A Competency-Based Approach. Washington DC, USA: American Psychological Association.

Falender, C. A., Cornish, J. A. E., Goodyear, R., Hatcher, R., Kaslow, N. J., Leventhal, G., Shafranske, E., Sigmon, S. T., Stoltenberg, C., \& Grus, C. (2004). Defining competencies in psychology supervision: A consensus statement. Journal of Clinical Psychology, 60 (7), 771-785. doi: 10.1002/jclp.20013

Finfgeld, D. L. (2003). Metasynthesis: The state of the art - so far. Qualitative Health Research, 13 (7), 893-904. doi: 10.1177/1049732303253462

Fleming, I., \& Steen, L. (2004). Introduction. In I. Fleming \& L. Steen (Eds). Supervision and Clinical Psychology: Theory, Practice and Perspectives (pp. 1-14). East Sussex: Brunner-Routledge.

*Folkes-Skinner, J., Elliot, R., \& Wheeler, S. (2010). 'A baptism of fire': A qualitative investigation of a trainee counsellor's experience at the start of training. Counselling and Psychotherapy Research, 10 (2), 83-92. doi: 10.1080/14733141003750509

*Gray, L. A., Ladany, N., Walker, J. A., \& Ancis, J. R. (2001). Psychotherapy trainees’ experience of counterproductive events in supervision. Journal of Counseling Psychology, 48 (4), 371-383. doi: 10.1037/0022-0167.48.4.371 
Green, D. (2004). Organizing and evaluating supervisor training. In I. Fleming \& L. Steen (Eds). Supervision and Clinical Psychology: Theory, Practice and Perspectives (pp. 93-107). East Sussex: Brunner-Routledge.

Holloway, E. L. (1995). Clinical supervision: A systems approach. California, USA; SAGE Publications Ltd.

Holloway, E. L., \& Neufeldt, S. A. (1995). Supervision: Its contribution to treatment efficacy. Journal of Consulting and Clinical Psychology, 63 (2), 207-213. doi: 10.1037/0022006X.63.2.207

Jensen, L. A., \& Allen, M. N. (1996). Meta-synthesis of qualitative findings. Qualitative Health Research, 6 (4), 553-560. doi: 10.1177/104973239600600407

*Johnston, L. H., \& Milne, D. L. (2012). How do supervisee’s learn during supervision? A grounded theory study of the perceived developmental process. The Cognitive Behaviour Therapist, 5, 1-23. doi: 10.1017/S1754470X12000013

Kilminster, S. M., \& Jolly, B. C. (2000). Effective supervision in clinical practice settings: a literature review. Medical Education, 34, 827-840. doi: 10.1046/j.13652923.2000.00758.x

Knox, S., Burkard, A. W., Jackson, J. A., Schaak, A. M., \& Hess, S. A. (2006). Therapists-intraining who experience a client suicide: Implications for supervision. Professional Psychology: Research and Practice, 37 (5), 547-557. doi: 10.1037/07357028.37.5.547

Kumari, N. (2011). Personal therapy as a mandatory requirement for counselling psychologists in training: A qualitative study of the impact of therapy on trainees’ personal and professional development. Counselling Psychology Quarterly, 24 (3), 211-232. doi: 10.1080/09515070903335000 
Ladany, N., Ellis, M. V., \& Friedlander, M. L. (1999). The supervisory working alliance, trainee self-efficacy, and satisfaction. Journal of Counseling \& Development, 77, 447455. doi: 10.1002/j.1556-6676.1999.tb02472.x

Ladany, N., \& Lehrman-Waterman, D. E. (1999). The content and frequency of supervisor self-disclosures and their relationship to supervisor style and the supervisory working alliance. Counselor Education and Supervision, 38, 143-159. doi: 10.1002/j.15566978.1999.tb00567.x

Ladany, N., O’Brien, K. M., Hill, C. E., Melincoff, D., Knox, S., \& Petersen, D. A. (1997). Sexual attraction toward clients, use of supervision, and prior training: A qualitative study of predoctoral psychology interns. Journal of Counseling Psychology, 44 (4), 413-424. doi: 10.1037/0022-0167.44.4.413

Lambert, M. J., Whipple, J. L., Smart, D. W., Vermeersch, D. A., Nielsen, S. L., \& Hawkins, E. J. (2001). The effects of providing therapists with feedback on patient progress during psychotherapy: Are outcomes enhanced? Psychotherapy Research, 11, 49-68. doi: 10.1080/713663852

Larson, L. M., \& Daniels, J. A. (1998). Review of the counselling self-efficacy literature. The Counseling Psychologist, 26 (2), 179-219. doi: 10.1177/0011000098262001

*Marshall, J. P., \& Wieling, E. (2003). Marriage and family therapy students’ phenomenological experiences of cross-cultural supervision. Family Therapy, 30 (3), $167-187$.

Milne, D. L. \& James, I. A. (2000). A systematic review of effective cognitive-behavioural supervision. British Journal of Clinical Psychology, 39, 111-127. doi: $10.1348 / 014466500163149$ 
Milne, D. L., \& James, I. A. (2002). The observed impact of training on competence in clinical supervision. British Journal of Clinical Psychology, 41, 55-72. doi: 10.1348/014466502163796

Milne, D. L., Pilkington, J., Gracie, J., \& James, I. (2003). Transferring skills from supervision to therapy: A qualitative and quantitative $\mathrm{N}=1$ analysis. Behavioural and Cognitive Psychotherapy, 31, 193-202. doi: 10.1017/S1352465803002078

Morrissey, J., \& Tribe, R. (2001). Parallel process in supervision. Counselling Psychology Quarterly, 14 (2), 103-110. doi: 10.1080/09515070110058567.

*Murphy, M. J., \& Wright, D. W. (2005). Supervisees’ perspectives of power use in supervision. Journal of Marital and Family Therapy, 31 (3), 283-295. doi: 10.1111/j.1752-0606.2005.tb01569.x

*Nelson, M. L., \& Friendlander, M. L. (2001). A close look at the conflictual supervisory relationships: The trainee's perspective. Journal of Counseling Psychology, 48 (4), 384-395. doi: 10.1037//0022-0167.48.4.384

Noblit, G. W., \& Hare, R. D. (1988). Meta-ethnography: Synthesising qualitative studies. Newbury Park California, USA: SAGE Publications Ltd.

O’Donovan, A., Dyck, M., \& Bain, J. D. (2001). Trainees’ experience of postgraduate clinical training. Australian Psychologist, 38 (2), 149-156. doi: $10.1080 / 00050060108259647$

O’Donovan, A., Halford, W. K., \& Walters, B. (2011). Towards best practice supervision of clinical psychology trainees. Australian Psychologist, 46, 101-112. doi:10.1111/j.1742-9544.2011.00033.x

Patel, N. (2004). Difference and power in supervision: the case of culture and racism. In I. Fleming \& L. Steen (Eds). Supervision and Clinical Psychology: Theory, Practice and Perspectives (pp. 108-134). East Sussex: Brunner-Routledge. 
*Perry, C. W. (2012). Constructing professional identity in an online graduate clinical training program: Possibilities for online supervision. Journal of Systemic Therapies, 31 (3), 53-67. doi: 10.1521/jsyt.2012.31.3.53

Pistole, M. C., \& Watkins, C. E., Jr. (1995). Attachment theory, counseling process, and supervision. The Counseling Psychologist, 23, 457-478. doi: $10.1177 / 0011000095233004$

Pope, C., Mays, N., \& Popay, J. (2007). Synthesizing Qualitative and Quantitative Health Evidence. New York, USA: Open University Press.

Rao, D., Feinglass, J., \& Corrigan, P. (2007). Racial and ethnic disparities in mental illness stigma. Journal of Nervous and Mental Disease, 195 (12), 1020-1023. doi: 10.1097/NMD.0b013e31815c046e

Ratcliff, D. A., Wampler, K. S., \& Morris, G. H. (2000). Lack of consensus in supervision. Journal of Marital and Family Therapy, 26 (3), 373-384. doi: 10.1111/j.17520606.2000.tb00306.x

*Reichelt, S., \& Skjerve, J. (2001). Supervision of inexperienced therapists. The Clinical Supervisor, 19 (2), 25-43. doi: 10.1300/J001v19n02_02

*Rhodes, P., Nge, C., Wallis, A., \& Hunt, C. (2011). Learning and living systemic: Exploring the personal effects of family therapy training. Contemporary Family Therapy, 33, 335-347. doi: 10.1007/s10591-011-9166-2

Roth, A., \& Fonagy, P. (1996). What works for whom? London: Guildford.

Sandelowski, M., \& Barroso, J. (2007). Handbook for Synthesizing Qualitative Research. New York, USA: Springer Publishing Company.

Sandelowski, M., Docherty, S., \& Emden, C. (1997). Qualitative metasynthesis: Issues and techniques. Research in Nursing \& Health, 20, 365-371. doi: 10.1002/(SICI)1098240X(199708)20:4\%3C365::AID-NUR9\%3E3.0.CO;2-E 
Stromme, H., \& Gullestad, E. (2012). Disclosure or non-disclosure? The Scandinavian Psychoanalytic Review, 35 (2), 105-115. doi: 10.1080/01062301.2012.10662648

Thorne, S., Jensen, L., Kearney, M. H., Noblit, G., \& Sandelowski, M. (2004). Qualitative metasynthesis: Reflections on methodological orientation and ideological agenda. Qualitative Health Research, 14 (10), 1342-1365. doi: 10.1177/1049732304269888

Vallance, K. (2004). Exploring counsellor perceptions of the impact of counselling supervision on clients. British Journal of Guidance and Counselling, 32 (4), 559-574. doi: 10.1080/03069880412331303330

Walsh, D., \& Downe, S. (2006). Appraising the quality of qualitative research. Midwifery 22(2), 108-19. doi:10.1016/j.midw.2005.05.004

Wheeler, S. (2004). A review of supervisor training in the UK. In I. Fleming \& L. Steen (Eds). Supervision and Clinical Psychology: Theory, Practice and Perspectives (pp. 15-35). East Sussex: Brunner-Routledge.

Wheeler, S., \& Richards, K. (2007). The impact of clinical supervision on counsellors and therapists, their practice and their clients. A systematic review of the literature. Counselling and Psychotherapy Research: Linking research with practice, 7 (1), 5465. doi: 10.1080/14733140601185274

White, V., \& Queener, J. (2003). Supervisor and supervisee attachments and social provisions related to the supervisory working alliance. Counselor Education \& Supervision, 42, 203-218. doi: 10.1002/j.1556-6978.2003.tb01812.x

Willyard, C. (2011). Men: A growing minority? gradPSYC, 9 (1). Retrieved April 12, 2014, from http://www.apa.org/gradpsych/2011/01/cover-men.aspx

*Worthen, V., \& McNeill, B. W. (1996). A phenomenological investigation of "good" supervision events. Journal of Counseling Psychology, 43 (1), 25-34. doi: 10.1037/0022-0167.43.1.25 
*Wulf, J., \& Nelson, M. L. (2001). Experienced psychologists' recollections of internship supervision and its contributions to their development. The Clinical Supervisor, 19 (2), 123-145. doi: 10.1300/J001v19n02_07 
Table 1

Demographic Information of Participants Included within the Meta-synthesis

\begin{tabular}{|c|c|c|c|c|c|}
\hline Study & Sample & Age (years) & Ethnicity & Gender & Location \\
\hline Ancis \& Marshall 2010 & $\begin{array}{l}4 \text { doctorate trainees }(2 \mathrm{x} \\
\text { clinical, } 2 \mathrm{x} \text { counselling) }\end{array}$ & Range $=27-41$ & $\begin{array}{l}3 \text { European American } \\
1 \text { Asian American }\end{array}$ & $\begin{array}{l}2 \text { female } \\
2 \text { male }\end{array}$ & USA \\
\hline $\begin{array}{l}\text { Bottrill, Pistrang, Barker \& } \\
\text { Worrell } 2010\end{array}$ & $\begin{array}{l}14 \text { clinical psychology } \\
\text { trainees }\end{array}$ & Range $=26-32$ & $\begin{array}{l}12 \text { White } \\
1 \text { Mixed race } \\
1 \text { Asian British }\end{array}$ & $\begin{array}{l}10 \text { female } \\
4 \text { male }\end{array}$ & UK \\
\hline $\begin{array}{l}\text { Burkard, Knox, Hess \& } \\
\text { Schultz } 2009\end{array}$ & $\begin{array}{l}17 \text { professional psychology } \\
\text { trainees (6x clinical } \\
\text { psychology, 1x counsellor } \\
\text { education, 10x counselling } \\
\text { psychology) }\end{array}$ & $\begin{array}{l}\text { Range }=24-49 \\
\text { Mean }=34.41 \\
\mathrm{SD}=7.68\end{array}$ & $\begin{array}{l}16 \text { European American } \\
1 \text { Native American }\end{array}$ & $\begin{array}{l}7 \text { female } \\
10 \text { male }\end{array}$ & USA \\
\hline $\begin{array}{l}\text { De Stefano, D’Iuso, Blake } \\
\text { Fitzpatrick, Drapeau \& } \\
\text { Chamodraka } 2007\end{array}$ & $\begin{array}{l}8 \text { counselling psychology } \\
\text { trainees }\end{array}$ & Range $=23-28$ & 8 Anglo-European & $\begin{array}{l}5 \text { female } \\
3 \text { male }\end{array}$ & Canada \\
\hline $\begin{array}{l}\text { Folkes-Skinner, Elliott \& } \\
\text { Wheeler } 2010\end{array}$ & 1 trainee counsellor & 50 & Not stated & 1 female & UK \\
\hline $\begin{array}{l}\text { Gray, Ladany, Walker \& } \\
\text { Ancis } 2001\end{array}$ & 13 psychotherapy trainees & $\begin{array}{l}\text { Range }=23-29 \\
\text { Mean }=25.92 \\
\mathrm{SD}=2.10\end{array}$ & $\begin{array}{l}12 \text { White } \\
1 \text { person of colour }\end{array}$ & $\begin{array}{l}10 \text { female } \\
3 \text { male }\end{array}$ & USA \\
\hline Johnston \& Milne 2012 & 7 trainee clinical & Mean $=26.71$ & Not stated & 7 female & UK \\
\hline
\end{tabular}




\begin{tabular}{|c|c|c|c|c|c|}
\hline Study & Sample & Age (years) & Ethnicity & Gender & Location \\
\hline & psychologists & $\mathrm{SD}=2.06$ & & & \\
\hline \multirow[t]{4}{*}{ Marshall \& Wieling 2003} & 12 marriage and family & Mean $=32$ & 8 Anglo-American & 8 female & USA \\
\hline & therapy trainees & Range $=24-49$ & 1 Latino/Hispanic & 4 male & \\
\hline & & & 1 African American/Black & & \\
\hline & & & 2 Other & & \\
\hline \multirow[t]{2}{*}{ Murphy \& Wright 2005} & 11 family therapy trainees & Range $=23-38$ & 11 Caucasian & 8 female & USA \\
\hline & (masters \& doctoral) & & & 3 male & \\
\hline Nelson \& Friedlander & 13 psychology trainees & Range $=29-52$ & 11 White & 9 female & USA \\
\hline \multirow[t]{2}{*}{2001} & (masters and doctoral) & Mean $=37$ & 1 Chicano/a & 4 male & \\
\hline & & $\mathrm{SD}=7$ & 1 Asian American & & \\
\hline \multirow[t]{2}{*}{ Perry 2012} & 9 trainees of online graduate & Range $=26-61$ & Not stated & 5 female & USA \\
\hline & clinical training program & Mean $=34.8$ & & 4 male & \\
\hline Reichelt \& Skjerve 2001 & 18 psychology interns & Not stated & Not stated & Not stated & Norway \\
\hline Rhodes, Nge, Wallis \& & 24 family therapy trainees & Range $=23-51$ & Not stated & 21 female & Australia \\
\hline Hunt 2011 & & Mean $=27.4$ & & 3 male & \\
\hline \multirow[t]{2}{*}{ Worthen \& McNeill 1996} & 8 counselling trainees & Range $=23-54$ & 8 European-American & 4 female & USA \\
\hline & & & & 4 male & \\
\hline \multirow[t]{2}{*}{ Wulf \& Nelson 2001} & 6 licensed psychologists & Range $=29-33$ & Not stated & 3 female & USA \\
\hline & & & & 3 male & \\
\hline
\end{tabular}


Table 2

Description of which studies contributed to each of the key concepts, which are:

1: Supervision as a learning opportunity, 2: Supervisory relationship, 3: Power in supervision, 4: Impact of supervision

Concepts

Papers

\begin{tabular}{llll}
\hline 1 & 2 & 3 & 4
\end{tabular}

Ancis \& Marshall 2010

$\begin{array}{cccc}\mathrm{X} & \mathrm{X} & \mathrm{X} & \mathrm{X} \\ \mathrm{X} & \mathrm{X} & \mathrm{X} & \\ & & & \\ \mathrm{X} & \mathrm{X} & \mathrm{X} & \mathrm{X}\end{array}$

Burkard, Knox, Hess \& Schultz 2009

De Stefano, D’Iuso, Blake Fitzpatrick, Drapeau \& 1hamodraka $2007 \quad$ x $\quad$ x

Folkes-Skinner, Elliott \& Wheeler 2010

$\mathrm{X}$

Gray, Ladany, Walker \& Ancis 2001

Johnston \& Milne 2012

$\begin{array}{lll}\mathrm{X} & \mathrm{X}\end{array}$

Marshall \& Wieling 2003

$\mathrm{X}$

Murphy \& Wright 2005

$\mathrm{X} \quad \mathrm{X} \quad \mathrm{X}$

Nelson \& Friedlander 2001

Perry 2012

X

Reichelt \& Skjerve 2001

X X

Rhodes, Nge, Wallis \& Hunt 2011

$\mathrm{X} \quad \mathrm{X}$

Worthen \& McNeill 1996

X X

Wulf \& Nelson 2001

$\begin{array}{llll}\text { X } & \mathrm{X} & \mathrm{X} & \mathrm{X}\end{array}$ 


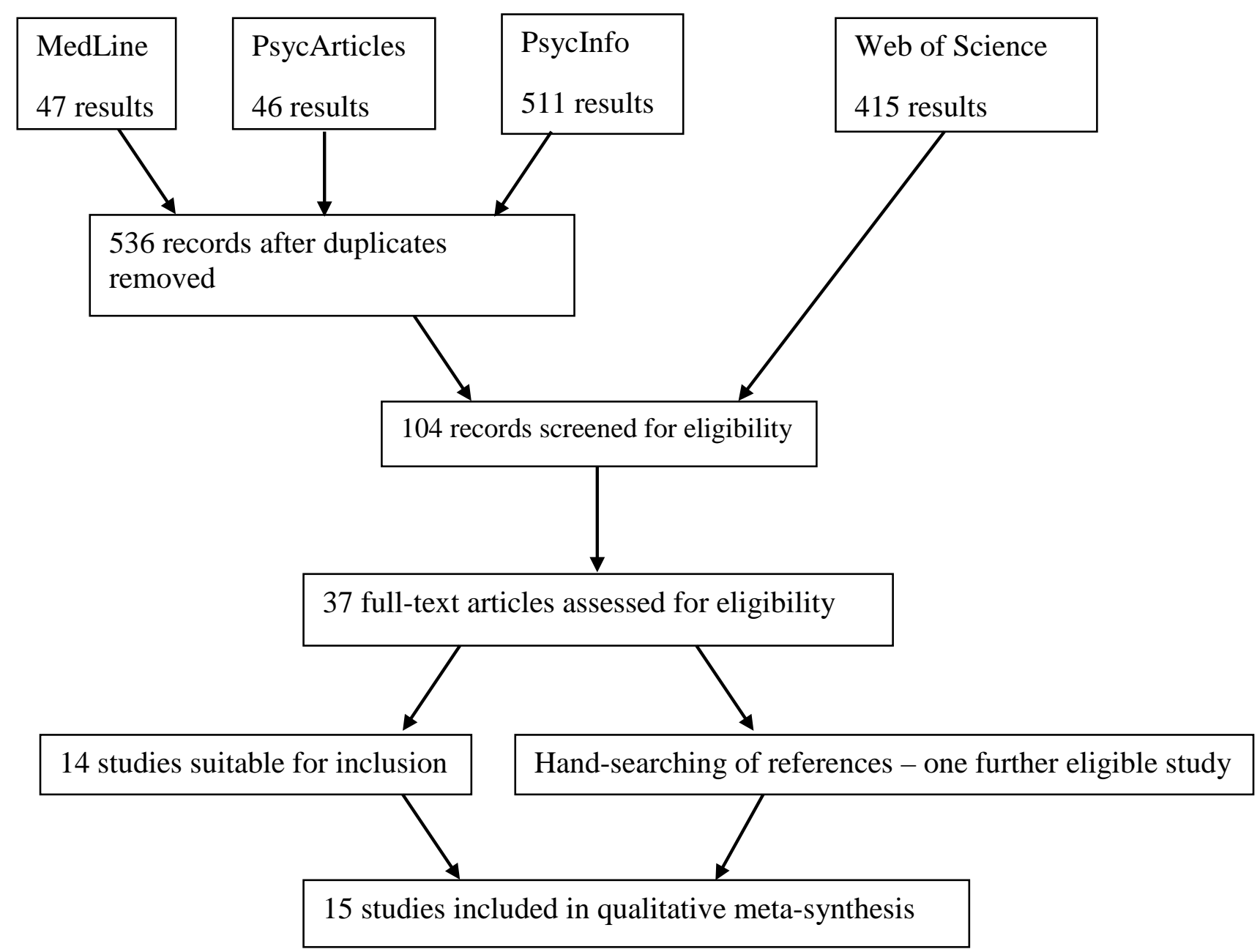

Figure 1. A Flowchart to Demonstrate Study Selection 
